\title{
Hey, pulmonologists and family doctors, please read me and see the data-It is a brave new world
}

\author{
Robert James Cerfolio, MD, MBA
}

\footnotetext{
From the Department of Cardiothoracic Surgery, University of Alabama at Birmingham College of Arts and Sciences, Birmingham, Ala.

Disclosures: Author has nothing to disclose with regard to commercial support.

Received for publication Nov 3, 2015; accepted for publication Nov 4, 2015; available ahead of print Dec 1, 2015 Address for reprints: Robert James Cerfolio, MD, MBA, Department of Cardiothoracic Surgery, University of Alabama At Birmingham, 703 19th St, S ZRB 739, Birmingham, AL 35294-0016 (E-mail: rcerfolio@ uabmc.edu).

J Thorac Cardiovasc Surg 2016;151:725

$0022-5223 / \$ 36.00$

Copyright (c) 2016 by The American Association for Thoracic Surgery

http://dx.doi.org/10.1016/j.jtcvs.2015.11.002
}

We surgeons know that you think of lung volume reduction surgery (LVRS) as dangerous - and you are right, it was, but not today. We all know that you have all seen patients with severe emphysema who have undergone a median sternotomy and LVRS on the ventilator postoperatively who have eventually died-but none recently, not today. It is a brave new world. And you are ultimately in control of what surgeon you send your patient to for surgical consultation. Please reconsider the role of LVRS for carefully selected patients.

The data for LVRS in the past few years suggest that minimally invasive surgery has changed the landscape; it is a brave new world. LVRS remains the standard of care for patients with heterogeneous emphysema; however, a recent review of the Society of Thoracic Surgery Database identified only 538 LVRS procedures reported during an 8-year period. ${ }^{1}$ This comes out to about 67 patients a year-a year-in the entire Society of Thoracic Surgery Database_really? Even if only 1 in 10 referred patients underwent LVRS, that would still be only 670 patients referred for LVRS a year-really-in the entire United States. Is there any other disease state for which the standard of care is offered less frequently than is LVRS for emphysema?

In their important article in this month's issue of The Journal of Thoracic and Cardiovascular Surgery, Ginsburg and colleagues have shown that LVRS when chosen for properly selected patients and performed by general thoracic surgeons who specialized in minimally invasive techniques is safe, durable, and effective. Most important to referring physicians is that it is safe and improves quality of life. Most patients can go home and not to a nursing home

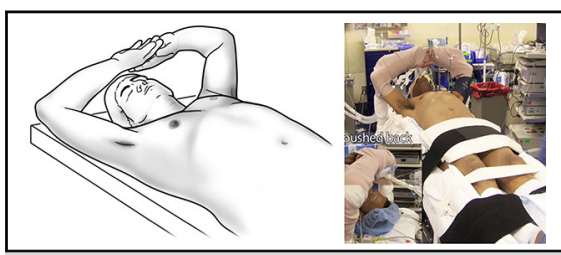

Patient positioning for bilateral lung volume reduction surgery.

\section{Central Message}

More patients should be referred for lung volume reduction surgery to surgeons who perform video-assisted thoracoscopic surgery.

See Article page 717.

See Editorials page 626 and 629.

postoperatively, and most breathe better. In addition, Ginsburg and colleagues show that the effects are durable.

Although this is a small, single-institution, retrospective series, these are all the data that we as surgeons have been afforded to present because of the current referral patterns (or lack of referral patterns) in the United States. My experience at the University of Alabama at Birmingham, as well as the experience of other minimally invasive general thoracic surgeons, has been similar.

Finally, what other options do we have to offer these patients who have stopped smoking, completed physical therapy, and have minimal comorbidities in addition to their heterogeneous emphysema? Oxygen with continued physical therapy and more inhalers all have little effect. And the great promise of bronchogenic valves has not been fulfilled-not today. Please consider referring for LVRS at the center of excellence closest to you. It is a brave new world.

\section{Reference}

1. Decker MR, Leverson GE, Jaoude WA, Maloney JD. Lung volume reduction surgery since the National Emphysema Treatment Trial: study of Society of Thoracic Surgeons Database. J Thorac Cardiovasc Surg. 2014;148:2651-8.e1. 